\title{
Application of Assessment as Learning In Mathematics Instruction
}

\author{
Benidiktus Tanujaya \\ Department of Mathematics Education, Universitas Papua \\ Manokwari,, Indonesia \\ benidiktus.0903@gmail.com
}

\begin{abstract}
This research was conducted to determine the best approach to implement the assessment as learning in mathematics instruction. Assessment as learning is a classroom-based assessment that applies the principles of self-assessment by students on each of the instruction process. The main principle in the assessment as learning is that students know what they know and what they do not know. Based on both of these, students can improve their learning achievement independently with the teacher's guidance. There are two approaches taken in the application of this assessment in mathematics instruction namely: group assignments and individual assignments. Group assignment is a task assigned by the teacher to be done as a group, while the individualassignment is a task to be done individually. Each assignment consists of presenting and problem solving. The results showed that the presenting task that was done in groups results as the best learning activities, whereas the highest learning achievement was taken place when students work the problem solving individually.
\end{abstract}

Keywords- Assessment as learning, Mathematics instruction.

\section{INTRODUCTION}

In the last decade, there has been a rapid change in social, economic, cultural, political, and technological. The situation means that education has been subjected to change. As society changes, teachers realize that they have to make changes to face these changes, as well as mission of school. Today's mission of schools have to less focused on merely sorting students and more focused on helping all students success in meeting standards. In order accomplish the mission; changes in various aspects of education, including changes in instruction are required.

Nowadays teacher's instruction tends to follow a general and predictable pattern. The instruction begins with teaching, followed by evaluating the students' understanding on the teaching material, making assessment on students' achievement based on the evaluation result (classroom assessment), and then moving on to the next unit of tlearning material. In these cases, classroom assessment is considered as a mechanism for providing an index of learning only. Moreover, [1] stated that historically, a major role of assessment has been to detect and highlight differences in student learning in order to rank students according to their achievement.
Assessment is not only aimed to determine the rank and grade, but more importantly to achieve other functions in educational process. Reference [2] Newton, assessment has been used for multiple purposes, such as providing student grades, system monitoring, student placement or monitoring, determining interventions, improving teaching and learning, or providing individual feedback to students and their parents. Meanwhile, [3] stated that assessment is process of gathering information that accurately reflects how well a student is achieving the curriculum expectations in a subject or course. Thus, there are some purposes of assessment, although the primary purpose of assessment is basically to improve student learning.

Based on its purpose, assessment is classified into three types, namely the assessment of learning (Aol), assessment for learning (AfL), and assessment as learning (AaL).The purpose of AoL is to measure, certify, and report the level of students' learning, so that reasonable decisions on students' achievement can be made, whereas in AfL, teachers use assessment as an investigative tool to find out what their students know and can do as much as they can, and what confusions, preconceptions, or gaps they might have [4]. The principal distinction between the two assessments is that AFL is used in making decisions that affect instruction in the near future, while AoL is used in recording and reporting material has been learned. In short, the nature of AoL is determined by what the information is used for.

Moreover, reference [5] stated that AfL is a vital component of effective teaching practice as teachers and students cannot avoid giving and getting feedback from any learning activity. AfL is concerned with practices that maximize the value of the feedback process to ensure that learning is optimized. The feedback includes the informal and formal one. Oral comments given immediately to learners as they think through problems are examples of formal feedback, whereas written note is an example of formal feedback. Written feedback such as rubrics is an instrument that help to clarify and scaffold learning and assessment objectives.

Reference [6], feedback is an important part of the learning cycle, but both students and teachers frequently express disappointment and frustration in relation to the conduct of the feedback process. Students sometimes complain that the feedback is 
unhelpful or unclear, and even demoralizing. Additionally, students sometimes report that they are not given guidance to use feedback to improve their subsequent performances. Even worse, students sometimes note that the feedback provided is too late and irrelevant. On the other hand, lecturers frequently comment that students are not interested in feedback comments and are only concerned with the grade. Furthermore, lecturers sometimes express frustration since students do not incorporate feedback advice into subsequent tasks.

On the other hand, AaL focuses on students and emphasizes assessment as a process of metacognition (knowledge of one's own thought processes) for students. AaL emerges from the idea that learning is not just a matter of transferring ideas from someone who is knowledgeable to someone who is not, but mainly an active process of cognitive restructuring that occurs when individuals interact with new ideas. AaL is based on research about how learning happens, and is characterized by students reflecting on their own learning and making adjustments so that they achieve deeper understanding [4]. As an important part of the instruction, the teacher plays an important role in the successful implementation of AaL. Teachers engage in AaL by helping students develop their capacity to be independent, autonomous learners who are able to set individual goals, monitor their own progress, determine next steps, and reflect on their thinking and learning [3]. There are some instruments in the implementation of AaL that teachers can utilize to help students, such as: presentations, conferences, essays, demonstrations, interviews, observations, quizzes, tests, and examinations. When applying these instruments, teachers perform an observation to obtain information about what students already known and what they have not known. Teachers can also find information about students understanding through various instruction activities, namely comments, explanations, questions, answers, and other students' activities in the classroom.

\section{METHOD}

The research was conducted using action research method. Action research (AR) including classroom action research (CAR) has many definitions, depend on the experts and field studies. The class action research also called teacher research or teacher as researcher is an approach designed to develop and improve teaching and learning in order to improve students' learning outcome that performed in several stages.

In this study, the CAR was implemented in six-step process of consciously and deliberately as proposed by [7], namely planning, taking actions, fact finding (data analysis and reflexing), revising plan, follow-up actions, and further analysis.

\section{A. Planning}

Planning was conducted in three stages. Firstly, the instrument preparation activities, which is a development assessment as learning. The assessment is adapted to learning materials and learning approaches used. The assessment must concurrent and integrate with learning material. Secondly, the determination of the success criteria of study. Success criteria used are student activity and learning achievement. Finally, learning goal discussion with students.

\section{B. Taking Actions}

The research consists of four actions and each actions consists of two cycles. The actions taken in the application of this assessment were group presentation, individual presentation, group problem- solving, and individual problem solving.

\section{Fact-finding}

After presentation and problem solving, students undertook a self-evaluation. Reference [8], selfevaluation is a process by which the student gathers information about, and reflects on his or her own learning. There are four criteria that are used to perform a self-evaluation, namely knowledge, skills, communication, and insight. Some samples of question adapted and developed from Paul's guidance in maintaining focus on the learning outcome [4], as selfevaluation:

Knowledge: Do I understand operations with ............, and why are they important to learn? What are some prior knowledge that I need to understand.........? What are some concepts that I need to understand it well to have a comprehensive knowledge? Do I ask thoughtful questions to help me understand better?

Skills: Can I do operation with ............, and know when to use them? Have I done the test using the procedure properly? Am I sure that my work does not contain calculation errors? What are the mistakes that I do? Why do I (still) do such mistakes?

Communication: Have I presented my task and explained my idea clearly and accurately so that other can understand? Can I show my understanding in picture, in writing, in speaking, and in numbers and symbols? Have I used correct mathematical model?

Insight: Can I find alternative ways to solve the problem? Can I use the formula to solve a different problem? Do I understand ........... well enough to use them (it) in different contexts?

In addition to the students' self-evaluation, teachers carry out observations. The observations were made by observing the student activity in learning process. The observations were carried out to ensure the learning was done well and was used to revise plan if necessary.

\section{Revising plan}

Revising plan was conducted based on the result of the observations. There are three possibilities in this phase, namely: change the planning, modify the 
planning, and continue the action without any changes at all.

\section{E. Follow-up actions}

Follow-up action was conducted based on the result of revising plan. Through this step, the study was also conducted to obtain data on the evaluation of student success in learning.

\section{F. Further analysis}

Besides improving the instruction process, further analysis on the data was also conducted in order to evaluate the students' learning success. Students learning success is evaluated by using two indicators, namely the student activity and student achievement. Student activity were evaluated by using observation guidelines developed by [7], while the learning achievement carried out by using a test. The test are arranged in the form of essays and evaluated by using a holistic rubric. The data obtained from the test results were analyzed by using statistical techniques $t$ test, to test scores of students among the four groups.

The subject of the research was 30 students who took mathematical statistics course at Mathematics Education Department, University of Papua. Mathematical statistics is a course that applies mathematics into statistics. Mathematical techniques which are used for the course include mathematical analysis, linear algebra, stochastic analysis, differential equations, and measure-theoretic probability theory.

\section{RESUlt AND DisCUSSION}

The research result shows that the implementation of AaL tends to increase student's instruction activities and student's achievement. There are three results of observation and test, where result of observations presented in two studies, students' weaknesses and student's activities, while the test results was used to measure of student's learning achievement. Another result of the research was the procedure application of $\mathrm{AaL}$ in mathematics instruction.

\section{A. The student's weaknesses}

Based on the observations, there are two main problems of the student's weaknesses during discussions and working on test questions, namely:

- Students seem still face difficulty in understanding the problem.

The main weakness is they misunderstand the purpose of questions. Reference [9] understanding the problem is an important step in solving mathematical problems. Understanding the question is a crucial aspect in problem-solving. The question needs to be understood, so that the problem could be solved.

- Students have not been able to use the formula that has been studied.
In this case, students could not apply to similar formula on different problems appropriately. In order to be able to use the formula proficiently, the students need to do a lot of practices. Reference [9] stated that solving the mathematical problem is a practical art, like swimming, or skiing, or playing the piano: you can learn it by imitation and practice. If you wish to learn swimming you have to go into the water. If you wish to become a problem solver to have to solve problem. It may be easy to imitate a solution of a problem by solving closely similar problem. Such imitating action may be more difficult and scarce if the similarity of the problem is not so close.

\section{B. Student's Activities}

Student's activities are number of things that students can do to achieve the success of the learning process. Student activities are also the efforts of students in learning. There are four indicators used to evaluate the student's activities in the study, namely: asking question, respond to question, delivering opinion, and debating average of student's activities on four actions as presented in Table I.

TABLE I. AVERAGE PERCENTAGE OF STUDENT'S ACTIVITIES ON FOUR ACTIONS OF INSTRUCTION.

\begin{tabular}{|l|c|c|c|c|}
\hline \multirow{2}{*}{ Indicator } & \multicolumn{4}{c|}{ Action } \\
\cline { 2 - 5 } & A & B & C & D \\
\hline Asking questions & 45 & 40 & 42 & 44 \\
\hline Respond to question & 75 & 70 & 80 & 68 \\
\hline Delivering opinion & 50 & 45 & 48 & 50 \\
\hline Debating & 35 & 30 & 30 & 25 \\
\hline
\end{tabular}

\section{Explanation}

A: Presenting group assignment;

B: Problem solving on group assignment;

$\mathrm{C}$ : Presenting individual assignment;

D: Problem solving on individual assignment.

Table 1 shows that students are more active when they are presenting the task on group compared to others, except for indicators respond to the question. Unlike individual presentation, in a group presentation students are involved in a lot of careful discussion, note making, and other activities. The advantage of group presentations over normal presentations is students have an opportunity to collaborate with their peers or colleagues.

\section{Student's Achievement}

There are many variables that can impact the success of student achievement, but the most influential is classroom instruction. Classroom instruction consists of preparation, implementation, and evaluation of learning. System of evaluation utilized in this study is the assessment as learning by using four approaches. Results of research on student achievement in some statistics are presented in Table 2. 
TABLE II. AVERAGE PERCENTAGE OF STUDENT'S ACTIVITIES ON FOUR ACTIONS OF INSTRUCTION.

\begin{tabular}{|c|c|c|c|c|}
\hline \multirow{2}{*}{ Actions } & \multicolumn{4}{|c|}{ Statistic } \\
\cline { 2 - 5 } & Min & Max & Mean & St.dev \\
\hline Action A & 49 & 77 & 63,00 & 6,83 \\
\hline Action B & 52 & 78 & 63,53 & 6,34 \\
\hline Action C & 56 & 78 & 67,10 & 7,10 \\
\hline Action D & 58 & 80 & 70,50 & 6,28 \\
\hline
\end{tabular}

Based on Table II, students who conduct problem solving on individual assignment have the best statistics value compared to the statistics of students in the three other groups. Students in the individual assignment group have a maximum, minimum, and average value of the highest with the smallest standard deviation.

Moreover, the result of statistical test using the test shows that the performance of students who conduct problem solving on assignment individually is significantly better than to the performance of students in other groups. Thus, it can be stated that among the four groups, students who conduct problem solving on individual assignments produce the best performance in applying the AaL.

\section{Application of Assessment as Learning}

Based on the observation and evaluation, there are several things concerning on the application of the AaL obtained in mathematics instruction, especially the procedure of AaL as follows:

Preparation: Some aspect should be prepared before applying the AaL. First of all, the assessment should be concurrent and integrated into instruction. Teacher should explain learning goals and success criteria to students before the instruction. It should be done at the outset of learning to ensure that students and teachers have a common and shared understanding of these goals and criteria as learning progresses. Teachers should also use assessment in order to inform instruction, to guide next steps, and to help students monitoring their progress towards achieving their learning goals.

Observation: Observation is an acquisition of information from a primary source, in these case students. Teachers should collect information about student's ability. The observation should be done before, during, and at or near the end of a period of instruction. The information is collected by using a variety of assessment strategies and tools.

Data analysis: Data and information about evidence of learning collected should be analyzed and interpreted.

Tutoring: Teachers should tutoring students to give and receive specific and timely descriptive feedback about their learning. Teacher should also help students to develop skills of self-assessment.

\section{CONCLUSION}

The results of research and discussion concluded that students presenting in task groups is the best learning activities, whereas the highest learning achievement was students working on the problem solving individually.

Moreover, assessment as learning has not been completely applied to the students in mathematics instruction. Students still need guidance from teachers. Students still face difficulties to know what they already known and what they have not known. However, there are some things that need to be conducted in implementing the $\mathrm{AaL}$ in mathematics instruction, namely preparation, observation, data-analyzed, and tutoring.

\section{REFERENCES}

[1] R. Stiggins, "Assessment through the Student's Eyes," Education Leadership, vol. 64, no. 8, pp. 22-26, 2007.

[2] P. E. Newton, "Clarifying the purposes of educational assessment.," Assessment in Education: Principles, Policy and Practice, vol. 14, no. 2, pp. 149-170, 2007.

[3] OME, Growing Success: Assessment, Evaluation, and Reporting in Ontario School, Ontario: The Ministry of Education's, 2010.

[4] L. Earl and S. Katz, "Rethinking Classroom Assessment with Purpose in Mind: Asessment of Learning, Assessment for Learning, Assessment as Learning," Western and Northen Canadian Protocol for Collaboration Education, 2006.

[5] IGSCE, "Assessment for Learning: Education Brief 2," Cambridge International Examinations, 2015.

[6] D. Spiller, Assessment: Feedback to Promote Student Learning, New Zealand: Teaching Development Unit, 2009.

[7] B. Tanujaya and J. Mumu, Penelitian Tindakan Kelas: Panduan Belajar Mengajar dan Meneliti, Yogyakarta: Media Akademi, 2016.

[8] OCUP, Assessment Companion, The Ontario Curriculum Unit Planner, Canada: Nipissing University, 2002.

[9] G. Polya, Mathematical Discovery on Understanding Learning and Teaching Problem Solving, New York: John Wiley and Sons, 1981. 
